INVITED ARTICLE

\title{
Reversal of Anticoagulants in Critical Care
}

\author{
Binila Chacko ${ }^{1}$, John Victor Peter ${ }^{2}$, Kandasamy Subramani ${ }^{3}$
}

\begin{abstract}
There has seen an increase in anticoagulant consumption worldwide over the past few decades. With this widespread utilization of anticoagulants, clinicians are increasingly likely to encounter situations where anticoagulants would need to be withheld. This includes emergency and elective procedures or surgeries as well as major or minor bleeding as a direct result of over anticoagulation or consequent to other intercurrent illnesses such as sepsis or trauma with multiorgan failure, where the anticoagulant may contribute to coagulation abnormalities. Clinicians are required to have a thorough understanding of the indications for anticoagulant prescription, drug interactions and monitoring, indications and options of reversal of anticoagulation and management of bleeding in the situations described above. Once the acute process is managed, the ongoing need and timing of reinitiation of anticoagulation is also crucial. This article provides an overview on the indications for reversal of anticoagulation, the agents used for reversal and the timing of reinitiation of anticoagulants.
\end{abstract}

Keywords: Anticoagulant, Critical care, Direct thrombin inhibitors, Protamine, Reversal, Vitamin K antagonists

Indian Journal of Critical Care Medicine (2019): 10.5005/jp-journals-10071-23257

\section{INTRODUCTION}

The past decade has seen an increase in anticoagulant consumption worldwide. In the United States alone, over 6 million patients who are on anticoagulants are at risk of complications from the same. ${ }^{1}$ The reason for this is twofold. First, with increasing longevity, we are seeing an increasing number of patients presenting with cardioembolic strokes, which contributes to about $15-30 \%$ of strokes. Atrial fibrillation is a major risk factor for the same. ${ }^{2,3}$ This has resulted in the use of anticoagulants in an attempt to prevent thrombosis and thromboembolism (venous thromboembolism and ischemic strokes), globally reported to be the foremost cause of morbidity and mortality. ${ }^{4}$ Second, given the convenience (lack of the need of regular monitoring), limited drug interactions and proven efficacy in thrombosis reduction, direct oral anticoagulants (DOAC) are increasingly being prescribed instead of warfarin. ${ }^{1}$ The inability to adjust dosing to optimal "therapeutic effect" may limit the ability to monitor for bleeding risk due to over anticoagulation.

With this widespread utilization of anticoagulants, clinicians are increasingly likely to encounter patients with major bleeding events. ${ }^{5}$ Several randomized controlled trials over the past decade comparing different DOAC agents with warfarin have reported major bleeding complications with both agents. ${ }^{5} \mathrm{~A}$ meta-analysis has shown that DOACs "significantly reduced the risk of major bleeding [relative risk (RR) $0.72, p<0.01$ ], fatal bleeding (RR 0.53 , $p<0.01$ ), intracranial bleeding (RR $0.43, p<0.01$ ), clinically relevant non-major bleeding (RR $0.78, p<0.01$ ), and total bleeding (RR 0.76 , $p<0.01)^{\prime \prime}$ when compared with warfarin..$^{5}$ It has also been found that intracranial hemorrhage $(\mathrm{ICH})$ was associated with a 4-fold increased risk of mortality compared with extra cranial major bleeds. ${ }^{6}$

There is hence an increased responsibility for the clinician to optimize care of these patients through careful prescribing, understanding drug interactions and monitoring, whenever possible, for over anticoagulation. This article will focus on indications for reversal of anticoagulation, the agents used for reversal and the timing of reinitiation of anticoagulants.
${ }^{1-3}$ Department of Critical Care Medicine, Christian Medical College, Vellore, Tamil Nadu, India

Corresponding Author: Binila Chacko, Department of Critical Care Medicine, Christian Medical College, Vellore, Tamil Nadu, India, e-mail: binilachacko@gmail.com

How to cite this article: Chacko B, Peter JV, Subramani K. Reversal of Anticoagulants in Critical Care. Indian J Crit Care Med 2019;23(Suppl 3):S221-S225.

Source of support: Nil

Conflict of interest: None

\section{How is Anticoagulation Reversed?}

Reversal of anticoagulation is done with pharmacological agents and/or blood products. Whilst it may appear that the clinical situation mandates reversal, it is important to assess if the anticoagulant is the cause of the bleed and/or is exacerbating the bleed. Two dimensions help in this process, namely pharmacokinetic properties of the anticoagulant and laboratory abnormalities. For example, in a patient with an acute bleed, who was on heparin or warfarin, a normal activated partial thromboplastin time (aPTT) or prothrombin time (PT)/International Normalized ratio (INR) and a time lapse of 4-5 half-lives since the last dose, there may not be a need for complete anticoagulant reversal. In these settings, it must also be kept in mind that thrombocytopenia and thrombocytopathy (e.g. drugs like aspirin, clopidogrel and systemic disease like uremia) can contribute to bleeding.

In a bleeding patient, it is useful to assess the level of anticoagulant activity. ${ }^{7}$ The traditional tests PT/INR and aPTT are recommended for monitoring adequacy of warfarin and heparin anticoagulation. These tests are however not helpful in the assessment of the level of anticoagulation of newer anticoagulants (direct thrombin inhibitors (DTIs) and factor Xa inhibitors). Whilst DTIs and factor Xa inhibitors can prolong aPTT and PT respectively, normal results cannot be used to establish lack of anticoagulant activity. If adequacy of anticoagulation needs to be assessed, dilute thrombin time and anti-Xa levels (calibrated with the drug of interest) respectively are recommended. Routine monitoring

(0) The Author(s). 2019 Open Access This article is distributed under the terms of the Creative Commons Attribution 4.0 International License (https://creativecommons. org/licenses/by-nc/4.0/), which permits unrestricted use, distribution, and non-commercial reproduction in any medium, provided you give appropriate credit to the original author(s) and the source, provide a link to the Creative Commons license, and indicate if changes were made. The Creative Commons Public Domain Dedication waiver (http://creativecommons.org/publicdomain/zero/1.0/) applies to the data made available in this article, unless otherwise stated. 
Table 1: Summary of anticoagulants and the agents used for reversal in major bleeding

\begin{tabular}{|c|c|c|c|c|c|}
\hline Anticoagulant & $\begin{array}{l}\text { Tests to pick } \\
\text { up excess AC } \\
\text { effect }\end{array}$ & Reversal agent and dose & $\begin{array}{l}\text { Prothrombin Com- } \\
\text { plex Concentrate }\end{array}$ & $\begin{array}{l}\text { Role for } \\
\text { Factor VIla }\end{array}$ & Role for FFP \\
\hline Vitamin K antagonists & PT/INR & $\begin{array}{l}\text { PCC with simultaneous administration of } \\
\text { Intravenous vitamin } \mathrm{K} 10 \mathrm{mg} \text { in } 25-50 \mathrm{ml} \text { NS } \\
\text { over } 15-30 \text { minutes }\end{array}$ & $\begin{array}{l}4 \text { factor-PCC (4F- } \\
\text { PCC) preferred to } 3 \\
\text { factor } \text { PCC }^{*} \text { and FFP }\end{array}$ & $\begin{array}{l}\text { Off-label use for } \\
\text { refractory bleed- } \\
\text { ing; weigh risks of } \\
\text { thromboembolism }\end{array}$ & $\begin{array}{l}\text { Indicated } \\
\text { only if } 4 \mathrm{~F} \mathrm{PCC} \\
\text { not available }\end{array}$ \\
\hline $\begin{array}{l}\text { Unfractionated hepa- } \\
\text { rin (UFH) }\end{array}$ & APTT & $\begin{array}{l}\text { Protamine sulfate } 1 \mathrm{mg} \text { for every } 100 \text { units } \\
\text { of UFH used within } 2 \text { hours of the bleed } \\
\text { (Maximum single dose } 50 \mathrm{mg} \text { to be infused } \\
\text { at } 5 \mathrm{mg} / \mathrm{min} \text { slowly over } 10 \text { minutes) }\end{array}$ & & $\begin{array}{l}\text { Off label use for } \\
\text { refractory bleed- } \\
\text { ing; weigh risks of } \\
\text { thromboembolism }\end{array}$ & $\begin{array}{l}\text { Can be given } \\
\text { if bleed- } \\
\text { ing persists } \\
\text { despite }\end{array}$ \\
\hline $\begin{array}{l}\text { Low-molecular } \\
\text { weight heparin } \\
\text { (LMWH) }\end{array}$ & $\begin{array}{l}\text { Anti-Xa } \\
\text { assay }\end{array}$ & $\begin{array}{l}1 \mathrm{mg} \text { protamine sulfate for every } 100 \text { anti-Xa } \\
\text { units (enoxaparin, } 100 \text { anti-Xa units }=1 \mathrm{mg} \text { ) } \\
\text { in the first } 8 \text { hours after LMWH; } 0.5 \text { mg pro- } \\
\text { tamine sulfate for every } 100 \text { anti-Xa units if } \\
\text { bleed } 8 \text { hours after LMWH }\end{array}$ & Not recommended & & protamine \\
\hline $\begin{array}{l}\text { Direct thrombin } \\
\text { inhibitors }\end{array}$ & $\begin{array}{l}\text { Thrombin } \\
\text { time } \\
\text { APTT }^{\dagger}\end{array}$ & $\begin{array}{l}\text { IV Idarucizumab ( } 2 \text { doses of } 2.5 \mathrm{~g} \text { ) for } \\
\text { dabigatran; Activated charcoal if within } 2 \\
\text { hours; Dialysis if prolonged thrombin time } \\
\text { despite idarucizumab or if idarucizumab not } \\
\text { available. } \\
\text { Other DTIs have short half-life, hence cessa- } \\
\text { tion of infusion is sufficient }\end{array}$ & & $\begin{array}{l}\text { Off-label use for } \\
\text { refractory bleed- } \\
\text { ing; weigh risks of } \\
\text { thromboembolism }\end{array}$ & $\begin{array}{l}\text { Not indi- } \\
\text { cated }^{13}\end{array}$ \\
\hline Factor Xa inhibitors & $\begin{array}{l}\text { Anti-Xa } \\
\text { assay } \\
\text { PT/INR }{ }^{\ddagger}\end{array}$ & $\begin{array}{l}\text { First line } 4 \mathrm{~F} \mathrm{PCC} \text { at } 50 \mathrm{IU} / \mathrm{kg} \text { or andexanet } \\
\text { alfa } 400 \mathrm{mg} \text { IV bolus over } 15-30 \text { minutes } \\
\text { followed by continuous infusion of } 4 \mathrm{mg} / \mathrm{min} \\
\text { for } 120 \mathrm{~min} \\
\text { Both should not be given together }\end{array}$ & $\begin{array}{l}\text { First line } 4 \mathrm{~F} \mathrm{PCC} \text { at } \\
50 \mathrm{IU} / \mathrm{kg}\end{array}$ & $\begin{array}{l}\text { Off-label use for } \\
\text { refractory bleed- } \\
\text { ing; weigh risks of } \\
\text { thromboembolism }\end{array}$ & Not indicated \\
\hline
\end{tabular}

AC, anticoagulant; PCC, prothrombin complex concentrate; INR, international normalized ratio; PT, prothrombin time; FFP, fresh frozen plasma; * Dosing as follows: INR 2-4: $25 \mathrm{IU} / \mathrm{kg}$; INR 4-6: $35 \mathrm{IU} / \mathrm{kg}$; INR >6: $50 \mathrm{IU} / \mathrm{kg}$; INR to be checked $30 \mathrm{~min}$ after administration and every 4 hours-repeat dose can be given if necessary; ${ }^{\dagger}$ prolonged APTT indicates excess anticoagulation, however normal APTT does not exclude anticoagulant effect; ${ }^{\ddagger}$ prolonged PT/INR indicates excess anticoagulation, however normal PT/INR does not exclude anticoagulant effect

of anticoagulant effect of DTIs and Factor Xa inhibitors is not advocated.

\section{Indications for Anticoagulation Reversal}

Broadly, anticoagulant reversal is indicated in three clinical settings namely, (a) prior to an elective surgical or invasive procedure, (b) acute bleeding (major or minor), and (c) prior to an emergency surgery or invasive procedure.

Major bleeding as defined by the Control of Anticoagulation Subcommittee refers to either bleeding with hemodynamic compromise and/or bleeding in a critical anatomic site (intracranial, pericardial, intraspinal, intraocular, retroperitoneal, intra-articular, or intramuscular with compartment syndrome) and/or an acute drop in hemoglobin by more than $2 \mathrm{~g} / \mathrm{dL}$ or the requirement of more than 2 units of blood or massive transfusion. ${ }^{8}$ While reversal is important in the situations described above, the risk of subsequent thromboembolic events due to reversal, ranging from $7.2-12 \%$ within 30 days from the event, should also be kept in mind. ${ }^{9,10}$ Thus the decision on when and how to restart anticoagulation following an episode of acute bleed is also important.

\section{Anticoagulation Reversal in Specific Clinical Settings}

\section{Major Bleed}

In major and life-threatening bleeds, all anticoagulants must be discontinued and reversal agents must be administered if available.
This should not delay fluid and blood resuscitation and local measures to control the bleeding whilst ensuring normothermia, normal acid base status and ionised calcium. In critical site bleeding, it is also important to liaise with the appropriate specialist for definitive management. Restrictive blood transfusions targeting Hemoglobin $>7 \mathrm{~g} / \mathrm{dL}$ (>8 $\mathrm{g} / \mathrm{dL}$ in patients with ischemic heart disease), ${ }^{11,12}$ platelet transfusion to maintain platelet counts $>50000 / \mathrm{mm}^{3}$ and cryoprecipitate to maintain fibrinogen $>100 \mathrm{mg} / \mathrm{dL}^{13}$ are advised. In patients with poor response to platelet transfusion or uremia, there may be a role in targeting a hemoglobin level $9-10 \mathrm{~g} / \mathrm{dL}$ to optimize interaction between platelets and endothelium. ${ }^{14} \mathrm{~A}$ summary of the recommended methods of anticoagulant reversal is provided in Table 1. Specific agents are discussed below.

\section{Vitamin K Antagonists}

Vitamin K restores the hepatic carboxylation of vitamin K dependent coagulation factors. It is recommended that $10 \mathrm{mg}$ of vitamin $\mathrm{K}$ is administered as an intravenous infusion in $25-50 \mathrm{~mL}$ of normal saline over 15-30 minutes. ${ }^{15}$ This can be given even before PT/INR results are available because the risks associated with vitamin $\mathrm{K}$ are low and alternate anticoagulation can be started if required. Intravenous Vitamin $\mathrm{K}$ has a more predictable and rapid reduction in INR as compared with oral or subcutaneous preparations. Since vitamin $\mathrm{K}$ does not immediately correct the coagulation, it is recommended that clotting factors are simultaneously replenished.

Prothrombin complex concentrate (PCC) is recommended in patients with serious bleeding and INR $>2$. Four-factor PCC (containing factors II, VII, IX and X) is preferred over 3-factor PCC 
(containing factors II, IX and X) in view of the more successful INR reversal, with less adverse events. ${ }^{16}$ Usual PCC dose ranges from 25 to 50 units/kg depending on patient weight and INR (INR 2-4: $25 \mathrm{U} / \mathrm{kg}$; INR 4-6: $35 \mathrm{U} / \mathrm{kg}$ and INR >6: $50 \mathrm{U} / \mathrm{kg}) .^{13}$ INR must be rechecked half an hour following PCC administration and every 4 hours subsequently.

Fresh frozen plasma (FFP) (initial dose $15-30 \mathrm{~mL} / \mathrm{kg}$ for rapid reversal) may be given if PCC is not available or during massive transfusions for severe bleeding. Since this amounts to a large amount of plasma for correction, $10-15 \mathrm{~mL} / \mathrm{kg}$ plasma has been used in some studies. ${ }^{13}$ Since FFP comes with the added risks of volume overload and transfusion reactions, with less adequate hemostasis and slower reduction of INR when compared with $\mathrm{PCC}^{17,18}$ this is not the preferred choice. While there is evidence to suggest that recombinant activated factor VII ( $\mathrm{rFVIla)}$ can rapidly correct supratherapeutic INR, ${ }^{19}$ it is not recommended for warfarinassociated bleeding because it does not supply all the vitamin $\mathrm{K}$-dependent factors, has a short half-life, is costly and there is some evidence (limited) of thromboembolic events following administration. ${ }^{20}$

\section{Heparin}

Protamine sulfate is licensed for reversal of unfractionated heparin (UFH). It works by preventing the interaction of heparin with antithrombin. This is given as a slow intravenous bolus at a dose calculated from the number of units of UFH received in the last 2 hours, with $1 \mathrm{mg}$ protamine sulfate neutralizing approximately $80-100$ units of UFH (maximum single dose $50 \mathrm{mg}$ to be infused at $5 \mathrm{mg} / \mathrm{min}$ slowly over 10 minutes). ${ }^{21}$ It is important to accurately calculate the protamine requirement, as protamine by itself is an anticoagulant. It is important to anticipate and manage complications of protamine infusion (hypotension, pulmonary hypertension and anaphylactic reactions especially in individuals with previous protamine exposure, fish allergies and following vasectomy).

Whilst protamine is less effective at reversing anti-Xa activity of low-molecular weight heparin (LMWH) it is still recommended for reversal given the absence of alternatives and the report of benefit from retrospective studies. ${ }^{22}$ The 8 th edition of the American College of Chest Physicians (ACCP) guidelines recommend $1 \mathrm{mg}$ protamine sulfate for every 100 anti-Xa units (for enoxaparin, 100 anti-Xa units equate to approximately $1 \mathrm{mg}$ ) in the first 8 hours after LMWH administration. ${ }^{23} \mathrm{~A}$ repeat dose of $0.5 \mathrm{mg}$ protamine for every 100 units can be given if bleeding persists or if the bleeding occurs 8 hours after the last dose of $\mathrm{LMWH}^{23}$

\section{Direct Thrombin Inhibitors}

Given the short half-lives of argatroban ( $t_{1 / 2} 45$ minutes) and bivalirudin ( $\mathrm{t}_{1 / 2} 25$ minutes), reversal can be achieved by stopping the infusion. Idarucizumab (an antibody fragment which mimics the structure of thrombin and binds to dabigatran with high affinity), at a dose of two $2.5 \mathrm{~g}$ aliquots, is licensed for rapid reversal of dabigatran in life threatening bleeding or emergency surgery. ${ }^{24}$ The RE-VERSE AD study ${ }^{25}$ found a $100 \%$ laboratory reversal and cessation of clinical bleeding within 4 hours. This should not be given to patients if the thrombin time is normal. There was a $6 \%$ risk of thrombotic complications postreversal of dabigatran activity. ${ }^{25}$ If idarucizumab is not available, PCC or FFP can be used in addition to supportive measures and drug cessation. Hemodialysis has also been suggested in patients with high drug activity since dabigatran has minimal protein binding. ${ }^{26}$

\section{Factor Xa Inhibitors}

This includes the direct Xa inhibitors (e.g. Apixaban, Edoxaban, Rivaroxaban) and indirect Xa inhibitors (e.g. fondaparinaux). There is no licensed reversal agent. In the case of severe bleeding or emergency surgery, andexanet alfa ${ }^{27}$ (binds and sequesters direct factor Xa inhibitors), at a dose of $400 \mathrm{mg}$ IV bolus over 15-30 minutes followed by continuous infusion of $4 \mathrm{mg} / \mathrm{min}$ for 120 mins OR 4-factor PCC at $50 \mathrm{U} / \mathrm{kg}$, can be considered for reversal. Both should not be combined together. Based on the limited trials, 4F-PCC at $50 \mathrm{U} /$ $\mathrm{kg}$ is suggested over $25 \mathrm{U} / \mathrm{kg}$ in view of better control of bleeding. ${ }^{28}$ In case these agents are not available, FFP can be given in the emergency setting. Given the prothrombotic effect of andexanet alfa and the absence of relationship between decreased factor $\mathrm{Xa}$ levels and hemostasis, andexanet is still not licensed for use.

There is limited data on reversal of Fondaparinaux. Whilst it has been shown that Vitamin $\mathrm{K}$ is not useful, the decision to use prohemostatic agents like activated PCC or rFVIla must be weighed against the risk of bleeding. Experimental drugs under investigation for reversal of DTIs, factor Xa inhibitors and LMWH include Ciraparantag ${ }^{29,21}$ and FXa ${ }^{116 L} \cdot 30$

\section{Non-major Bleeding}

The approach is largely dependent on clinical judgment and balancing the risks versus benefit of anticoagulant reversal at this point. The decision on withholding one to two doses of the anticoagulant and reversal depends on the thromboembolic risk of the patient, the site of the bleed (whether it can be controlled by local measures or not) and the need for hospitalisation. If it is determined that the patient need not be hospitalised or a procedure needed, the American College of Cardiology (ACC) Expert guidelines recommend continuing the oral anticoagulant. ${ }^{13}$ Specifically for warfarin, low dose (5-10 mg) intravenous vitamin $\mathrm{K}$ administration can be considered. There is limited data on partial reversal of other anticoagulants in this setting.

\section{No Bleeding with Evidence of Deranged Bleeding Parameters}

It is advised that a couple of doses of the anticoagulant are withheld. There is no role of blood products or reversal agents in this situation. However, if the INR is $>10$ and the patient does not have clinically significant bleeding, warfarin should be withheld and $2.5-5 \mathrm{mg}$ of oral vitamin $\mathrm{K}$ should be administered. This should reduce INR within 24-48 hours. ${ }^{31}$ If INR is between 4.5-10, the 2012 ACCP and the 2018 American Society of Haematology (ASH) guidelines ${ }^{31,32}$ suggest not to use vitamin $\mathrm{K}$ in this setting. Warfarin should be withheld; oral vitamin K $1-2.5 \mathrm{mg}$ can be considered in patients with a high risk of bleeding and low thromboembolic risk. There is however no evidence of benefit in a recent meta-analysis. ${ }^{33}$

\section{Elective Surgery and the Indication for Bridging Anticoagulation}

There is a lack of high quality evidence to guide ideal practice for this common but difficult problem. Broadly, anticoagulant interruption is recommended. In patients where the risk of thromboembolism is high (stroke or venous thromboembolism in the past 3 months, mechanical heart valves, $\mathrm{CHA}_{2} \mathrm{DS}_{2} \mathrm{VASc}$ score $>6$ or $\mathrm{CHAD}$ score $5-6$ ) as opposed to the bleeding risk, the clinician needs to first assess whether the surgery is indicated at that point of time. ${ }^{34}$ If indicated, it is recommended that the interruption of the anticoagulation be kept to the minimum duration. There may be a role for bridging 
anticoagulation with heparin (either unfractionated heparin or $\mathrm{LMWH}$ ) in such patients. This however is controversial given that the periprocedural bleeding: thrombosis risk is much higher with bridging anticoagulation (10:1 versus 5:1 without bridging). ${ }^{35}$ Additionally, the actual rate of peri-procedural thromboembolism for unbridged anticoagulant interruptions has been documented to be as low as $0.53 \% .^{35}$

IVC filter insertion is recommended in patients requiring emergency surgery with recent (within a month) venous thromboembolism who are likely to have a high bleeding risk with bridging anticoagulation.

\section{Systemic Illness in a Critically III Patient on Anticoagulants}

In critically ill patients with sepsis, following trauma, massive blood loss and massive transfusion or transfusion related coagulopathy, it may be difficult to ascertain the contribution of the anticoagulant and the systematic problem. Routine investigations like PT, APTT and fibrinogen assay may not be useful in this situation. Viscoelastic tests, namely thromboelastogram (TEG) and rotational thromboelastometry (ROTEM) may help in deciphering the aetiology of bleed - whether it is related to coagulation factors, platelets or fibrinolysis. ${ }^{36}$ ROTEM additionally offers 4 tracings: INTEM that tests the intrinsic pathway similar to APTT; EXTEM tests the extrinsic pathway similar to PT; FIBTEM demonstrates the contribution of fibrinogen on clot strength; APTEM can help in picking up hyperfibrinolysis. ROTEM also offers optional tests like HEPTEM that can help uncover coagulopathy unrelated to heparin (by eliminating the effect of heparin with heparinise) and ECATEM that tests anticoagulant activity of direct thrombin inhibitors. Both TEG and ROTEM also assess the contribution of platelets in clot formation, but to assess platelet function, a platelet function analysis should be used. Deciphering such information will help in precision management of coagulation in these critically ill patients.

\section{Reinitiation of Anticoagulants}

There is recent evidence to suggest that anticoagulant resumption with either warfarin or direct oral anticoagulants following a bleeding event has a lower risk of ischemic stroke than anticoagulant cessation. ${ }^{37}$ The decision to restart anticoagulants must be reassessed weighing the risks versus benefit of doing so.

In conditions with a low risk of thromboembolism, the ACC expert guidelines ${ }^{13}$ suggests stopping the anticoagulant. These conditions include paroxysmal atrial fibrillation with a low $\mathrm{CHA}_{2} \mathrm{DS}_{2}$ VASc score $<1$ or conditions which required anticoagulation temporarily.

In patients with high thrombotic risk (mechanical valve prosthesis -mitral or aortic valve+/-AF or prior stroke within 6 months; AF with high $\mathrm{CHA}_{2} \mathrm{DS}_{2}$ VASc SCORE $\geq 6$ or CHAD score 5-6 +/- stroke or TIA within 3 months; unprovoked or recurrent venous thromboembolism within 3 months +/-active cancer; prior thromboembolism with anticoagulant interruption; left heart thrombus; left ventricular assist device), ${ }_{1}^{13}$ there is an ongoing indication for anticoagulation. The clinician must evaluate the net benefit of restarting the anticoagulant and weigh the risks of rebleed against the risk of thromboembolism.

The clinician must also address reversible factors (concomitant antiplatelet therapy, renal insufficiency and drug interactions) that could have exacerbated the bleed.

\section{Timing of Restarting Anticoagulants}

Following an episode of major bleeding in patients with high thromboembolic risk, early anticoagulant reinitiation is recommended once hemostasis is achieved..$^{13}$ It is important to choose the right anticoagulant for the patient adjusting for organ function and drug interactions. It is also important to correct reversible factors such as vitamin $\mathrm{K}$ deficiency.

For patients with high re-bleeding risk (intracranial hemorrhage, inadequate and suboptimal hemostasis, lack of bleeding source identification, spontaneous onset of bleed) and high thromboembolic risk, unfractionated heparin infusion can be started within 1-3 days due to its short half-life and an available reversal agent if the patient rebleeds. Decisions following an intracranial hemorrhage are more challenging and need to be individualized. Amyloid angiopathy causing lobar hemorrhage, microbleeds and spontaneous intracranial hemorrhage $(\mathrm{ICH})$ have a higher risk of rebleeding. The risks of hemorrhage expansion are highest in the first hours and days after $\mathrm{ICH}$, while the risks of thromboembolism and recurrent $\mathrm{ICH}$ accumulate over time. There is a lack of consensus in this setting and minimal data on the optimal time, with suggested times ranging from 4 to 7 days $s^{38}$ to $10-30$ weeks. ${ }^{39}$ Most experts have concluded that anticoagulation can be restarted at 7-14 days. ${ }^{40}$

The timing of restarting anticoagulation following an emergency surgery with adequate hemostasis depends on the post procedural bleeding risk. For procedures with low bleeding risks, ACC recommends restarting anticoagulation 24 hours after the procedure. ${ }^{13}$ If the bleeding risk is higher, anticoagulation can be delayed for $48-72$ hours. $^{41}$

\section{Conclusion}

Bleeding complications related to overanticoagulation and emergent and elective indications for cessation of anticoagulant therapy are not uncommon in intensive care practice. An algorithmic approach would enable these situations to be managed appropriately. This process is more defined for conventional anticoagulants such as heparin and warfarin. The approach to and management of patients on newer anticoagulants is more challenging given the lack of ease of assessment of degree of anticoagulation as well as limited agents for reversal. More work is needed in this area.

\section{References}

1. Barnes GD, Lucas E, Alexander GC, Goldberger ZD. National Trends in Ambulatory Oral Anticoagulant Use. The American Journal of Medicine. 2015 Dec;128(12):1300-1302.

2. Wendelboe AM, Raskob GE. Global Burden of Thrombosis: Epidemiologic Aspects. Circ Res. Lippincott Williams \& Wilkins Hagerstown, MD; 2016 Apr 29;118(9):1340-1347.

3. Ustrell X, Pellisé A. Cardiac workup of ischemic stroke. Curr Cardiol Rev. 2010 Sep 17;6(3):175-183.

4. Milling TJ, Frontera J. Exploring indications for the Use of direct oral anticoagulants and the associated risks of major bleeding. Am J Manag Care. 2017 Apr 1;23(4):S67-S80.

5. Chai-Adisaksopha C, Crowther M, Isayama T, Lim W. The impact of bleeding complications in patients receiving target-specific oral anticoagulants: a systematic review and meta-analysis. Blood. 2014 Oct 9;124(15):2450-2458.

6. Gómez-Outes A, Lecumberri R, Suárez-Gea ML, Terleira-Fernández A-I, Monreal M, Vargas-Castrillón E. Case Fatality Rates of Recurrent Thromboembolism and Bleeding in Patients Receiving Direct Oral Anticoagulants for the Initial and Extended Treatment of Venous Thromboembolism. J Cardiovasc Pharmacol Ther. 2015 Mar 31;20(5):490-500. 
7. Funk DMA. Coagulation assays and anticoagulant monitoring. Hematology Am Soc Hematol Educ Program. 2012;2012:460-465.

8. Schulman S, Kearon C, Subcommittee on Control of Anticoagulation of the Scientific and Standardization Committee of the International Society on Thrombosis and Haemostasis. Definition of major bleeding in clinical investigations of antihemostatic medicinal products in non-surgical patients. J Thromb Haemost. John Wiley \& Sons, Ltd (10.1111); 2005 Apr;3(4):692-694.

9. Beyer-Westendorf J, Förster K, Pannach S, Ebertz F, Gelbricht V, Thieme $C$, et al. Rates, management, and outcome of rivaroxaban bleeding in daily care: results from the Dresden NOAC registry. Blood. American Society of Hematology; 2014 Aug 7;124(6):955-962.

10. Held C, Hylek EM, Alexander JH, Hanna M, Lopes RD, Wojdyla DM, et al. Clinical outcomes and management associated with major bleeding in patients with atrial fibrillation treated with apixaban or warfarin: insights from the ARISTOTLE trial. Eur Heart J. 2015 May 21;36(20):1264-1272.

11. Carson JL, Guyatt G, Heddle NM, Grossman BJ, Cohn CS, Fung MK, et al. Clinical Practice Guidelines From the AABB. JAMA. American Medical Association; 2016 Nov 15;316(19):2025-2035. doi: 10.1001/ jama.2016.9185

12. Villanueva C, Colomo A, Bosch A, Concepción M, Hernandez-Gea V, Aracil C, et al. Transfusion strategies for acute upper gastrointestinal bleeding. N Engl J Med. 2013 Jan 3;368(1):11-21.

13. FACC GFTM, FACC KWMM, MS ACM, PharmD PPD, FACC JUDM, MBBS JWE, et al. 2017 ACC Expert Consensus Decision Pathway on Management of Bleeding in Patients on Oral Anticoagulants. Journal of the American College of Cardiology. Elsevier; 2017 Dec 19;70(24):3042-3067.

14. Lozano M, Cid J. Alternative strategies to platelet transfusion. ISBT Science Series. 2016;11(Suppl 1):93-99.

15. Lubetsky A, Yonath H, Olchovsky D, Loebstein R, Halkin H, Ezra D. Comparison of Oral vs Intravenous Phytonadione (Vitamin K1) in Patients With Excessive Anticoagulation. Arch Intern Med. American Medical Association; 2003 Nov 10;163(20):2469-2473.

16. Jones GM, Erdman MJ, Smetana KS, Mohrien KM, Vandigo JE, Elijovich L. 3-Factor Versus 4-Factor Prothrombin Complex Concentrate for Warfarin Reversal in Severe Bleeding: A Multicenter, Retrospective, Propensity-Matched Pilot Study. J Thromb Thrombolysis. 4 ed. Springer US; 2015 Dec 31;42(1):19-26.

17. Goldstein JN, Refaai MA, Milling TJ, Lewis B, Goldberg-Alberts $R$, Hug $B A$, et al. Four-factor prothrombin complex concentrate versus plasma for rapid vitamin $\mathrm{K}$ antagonist reversal in patients needing urgent surgical or invasive interventions: a phase $3 \mathrm{~b}$, open-label, noninferiority, randomised trial. Lancet. 2015 May 23;385(9982):20772087.

18. Steiner T, Poli S, Griebe M, Hüsing J, Hajda J, Freiberger A, et al. Fresh frozen plasma versus prothrombin complex concentrate in patients with intracranial haemorrhage related to vitamin $\mathrm{K}$ antagonists (INCH): a randomised trial. The Lancet Neurology. 2016 May;15(6):566-573.

19. Rosovsky RP, Crowther MA. What is the evidence for the off-label use of recombinant factor VIIa ( $\mathrm{rFVlla}$ ) in the acute reversal of warfarin? ASH evidence-based review 2008. Hematology. American Society of Hematology; 2008;2008(1):36-38.

20. Dager WE, King JH, Regalia RC, Williamson D, Gosselin RC, White $\mathrm{RH}$, et al. Reversal of Elevated International Normalized Ratios and Bleeding with Low-Dose Recombinant Activated Factor VII in Patients Receiving Warfarin. Pharmacotherapy. John Wiley \& Sons, Ltd; 2006 Aug;26(8):1091-1098.

21. Greinacher A, Thiele T, Selleng K. Reversal of anticoagulants: an overview of current developments. Thromb Haemost. Schattauer GmbH; 2017 Nov 24;113(05):931-942.

22. van Veen JJ, Maclean RM, Hampton KK, Laidlaw S, Kitchen S, Toth $P_{\text {, }}$ et al. Protamine reversal of low molecular weight heparin: clinically effective? Blood Coagul Fibrinolysis. 2011 Oct;22(7):565-570.

23. Hirsh J, Bauer KA, Donati MB, Gould M, Samama MM, Weitz JI. Parenteral anticoagulants: American College of Chest Physicians Evidence-Based Clinical Practice Guidelines (8th Edition). Chest. 2008;141S-159S.
24. Pollack CV, Reilly PA, van Ryn J, Eikelboom JW, Glund S, Bernstein RA et al. Idarucizumab for Dabigatran Reversal - Full Cohort Analysis. N Engl J Med. Massachusetts Medical Society; 2017 Aug 3;377(5):431441.

25. PollackCV, Reilly PA, Weitz J..Dabigatran Reversal with Idarucizumab. N Engl J Med. Massachusetts Medical Society; 2017 Oct 26;377(17):16911692.

26. Stangier J, Rathgen K, Stähle H, Mazur D. Influence of Renal Impairment on the Pharmacokinetics and Pharmacodynamics of Oral Dabigatran Etexilate. Clin Pharmacokinet. Springer International Publishing; 2010 Apr;49(4):259-268.

27. Connolly SJ, Crowther M, Eikelboom JW, Gibson CM, Curnutte JT, Lawrence JH, et al. Full Study Report of Andexanet Alfa for Bleeding Associated with Factor Xa Inhibitors. N Engl J Med. Massachusetts Medical Society; 2019 Apr 4;380(14):1326-1335.

28. Levi M, Moore KT, Castillejos CF, Kubitza D, Berkowitz SD, Goldhaber $\mathrm{SZ}$, et al. Comparison of three-factor and four-factor prothrombin complex concentrates regarding reversal of the anticoagulant effects of rivaroxaban in healthy volunteers. J Thromb Haemost. John Wiley \& Sons, Ltd (10.1111); 2014 Sep;12(9):1428-1436.

29. Ansell JE, Bakhru SH, Laulicht BE, Steiner SS, Grosso MA, Brown $\mathrm{K}$, et al. Single-dose ciraparantag safely and completely reverses anticoagulant effects of edoxaban. Thromb Haemost. Schattauer $\mathrm{GmbH} ; 2017$ Jan 26;117(2):238-245.

30. Parsons-Rich D, Hua F, Li G, Kantaridis C, Pittman DD, Arkin S. Phase 1 dose-escalating study to evaluate the safety, pharmacokinetics, and pharmacodynamics of a recombinant factor Xa variant (FXa 116L). J Thromb Haemost. John Wiley \& Sons, Ltd (10.1111); 2017 Apr 25;15(5):931-937.

31. Witt DM, Nieuwlaat R, Clark NP, Ansell J, Holbrook A, Skov J, et al. American Society of Hematology 2018 guidelines for management of venous thromboembolism: optimal management of anticoagulation therapy. Blood Adv. 2018 Nov 27;2(22):3257-3291.

32. Holbrook A, Schulman S, Witt DM, Vandvik PO, Fish J, Kovacs MJ, et al. Evidence-based management of anticoagulant therapy: Antithrombotic Therapy and Prevention of Thrombosis, 9th ed: American College of Chest Physicians Evidence-Based Clinical Practice Guidelines. Chest. 2012 Feb;141(2 Suppl):e152S-e184S.

33. Khatib R, Ludwikowska M, Witt DM, Ansell J, Clark NP, Holbrook $A$, et al. Vitamin $K$ for reversal of excessive vitamin $K$ antagonist anticoagulation: a systematic review and meta-analysis. Blood Adv. 2019 Mar 12;3(5):789-796.

34. Spyropoulos AC, Douketis JD. How I treat anticoagulated patients undergoing an elective procedure or surgery. Blood. American Society of Hematology; 2012 Oct 11;120(15):2954-2962.

35. Rechenmacher SJ, Fang JC. Bridging Anticoagulation: Primum Non Nocere. Am Coll Cardiol. Elsevier Inc; 2015 Sep 22;66(12):1392-1403.

36. Drumheller BC, Stein DM, Moore LJ, Rizoli SB, Cohen MJ. Thromboelastography and rotational thromboelastometry for the surgical intensivist: A narrative review. J Trauma Acute Care Surg. 2019 Apr;86(4):710-721.

37. Hernandez I, Zhang Y, Brooks MM, Chin PKL, Saba S. Anticoagulation Use and Clinical Outcomes After Major Bleeding on Dabigatran or Warfarin in Atrial Fibrillation. Stroke. 2017 Jan;48(1):159-166.

38. AlKherayf F, Xu Y, Gandara E, Westwick H, Moldovan ID, Wells PS. Timing of vitamin $\mathrm{K}$ antagonist re-initiation following intracranial hemorrhage in mechanical heart valves: Systematic review and meta-analysis. Thromb Res. 2016 Aug;144:152-157.

39. Majeed A, Kim Y-K, Roberts RS, Holmström M, Schulman S. Optimal timing of resumption of warfarin after intracranial hemorrhage. Stroke. Lippincott Williams \& Wilkins; 2010 Dec;41(12):2860-2866.

40. Morgenstern LB, Hemphill JC III, Anderson C, Becker K, Broderick JP, Connolly ES Jr, et al. Guidelines for the Management of Spontaneous Intracerebral Hemorrhage. Stroke. 2010 Sep;41(9):2108-2129.

41. Doherty JU, Gluckman TJ, Hucker WJ, Januzzi JL Jr., Ortel TL, Saxonhouse SJ, et al. 2017 ACC Expert Consensus Decision Pathway for Periprocedural Management of Anticoagulation in Patients With Nonvalvular Atrial Fibrillation. Journal of the American College of Cardiology. 2017 Feb;69(7):871-898. 